\title{
Electrical Synapses between Dopaminergic Neurons of the Substantia Nigra Pars Compacta
}

\author{
Marie Vandecasteele, Jacques Glowinski, and Laurent Venance \\ Laboratoire de Neurobiologie Pharmacologique, Institut National de la Santé et de la Recherche Médicale, Collège de France, 75005 Paris, France
}

Spatiotemporal properties of dopamine release play a major role both in striatal and nigral physiology because dopamine is released from nerve terminals and dendrites of nigrostriatal dopaminergic (DA) neurons. Pioneering work revealed gap junctional communication (assessed by dye-coupling experiments) between DA cells in the substantia nigra pars compacta (SNc). However, direct evidence of functional electrical synapses between DA neurons is still lacking. In this study, gap junctional communication between DA neurons was investigated in rat brain slices. Tracer coupling was observed in postnatal day 5 (P5) to P10 and P15-P25 rats. Dual whole-cell patchclamp recordings revealed that $96 \%$ of DA neurons were coupled by electrical synapses in P7-P10 rats, and 20\% were coupled in P17-P21 rats. These electrical synapses were mainly symmetrical and displayed strong low-pass filtering properties. When spontaneous firing activity was monitored, no significant synchronization was observed. Nevertheless, an efficient modulation of the spontaneous firing frequency of the postsynaptic cell occurred during injection of hyperpolarizing and depolarizing currents in the coupled presynaptic cell. Together, these observations demonstrate the existence of a fast communication between SNc DA neurons through electrical synapses.

Key words: dopaminergic neuron; substantia nigra pars compacta; electrical synapse; paired recordings; gap junctions; connexin

\section{Introduction}

The basal ganglia are a highly interconnected network of subcortical nuclei involved in adaptative control of behavior, in which the substantia nigra pars compacta $(\mathrm{SNc})$ constitutes the main modulatory nucleus (Graybiel et al., 1990; Gerfen, 1992). The degeneration of nigrostriatal dopaminergic (DA) cells leads to Parkinson's disease (for review, see Obeso et al., 2000). DA neurons composing SNc mainly project to the dorsal striatum, a major input area of basal ganglia that selects relevant cortical information (Wilson, 1995). Dopamine potently modulates the processing of corticostriatal information (Reynolds and Wickens, 2002; Guzman et al., 2003).

Nigrostriatal DA neurons display two modes of discharge: a tonic background firing maintaining ambient dopamine levels in the striatum and a phasic firing (bursting activity) associated with brief high peaks of dopamine release, observed during appetitive learning and motivation-related behaviors (Gonon, 1988; Romo and Schultz, 1990; Ljungberg et al., 1992; Schultz et al., 1997).

Locally, dopamine released from dendrites regulates DA cell activity through DA autoreceptors (Skirboll et al., 1979; Cheramy et al., 1981). In addition, another mode of communication be-

Received June 3, 2004; revised Nov. 16, 2004; accepted Nov. 17, 2004

This work was supported by an Action Concertée Incitative "Jeune Chercheur" grant from the French Ministère de la Recherche, by Fondation de France Grant 20020111943, by the Institut National de la Santé et de la Recherche Médicale, and by the College de France. We thank Dr. Laurent Pezard for help with statistical analysis of nonlinear correlation; Anne-Marie Godeheu for technical assistance for histology; and Prof. Jean-Michel Deniau, Elodie Fino, Dr. Christian Giaume, Dr. Jasna Jerecic, and Prof. Istvan Mody for careful reading of this manuscript.

Correspondence should be addressed to Laurent Venance, Laboratoire de Neurobiologie Pharmacologique, Institut National de la Santé et de la Recherche Médicale U-114, Collège de France, 11 place Marcelin Berthelot, 75005 Paris, France. E-mail: laurent.venance@college-de-france.fr.

D0I:10.1523/JNEUROSCI.4167-04.2005

Copyright $\odot 2005$ Society for Neuroscience $\quad$ 0270-6474/05/250291-08\$15.00/0 tween DA neurons could be mediated by gap junctions. Indeed, an increasing body of evidence shows the existence of functional electrical synapses throughout the CNS not only between GABAergic interneurons (Gibson et al., 1999; Venance et al., 2000; Galarreta and Hestrin, 2001) but also between subsets of output neurons (Christie et al., 1989; Schmitz et al., 2001; Devor and Yarom, 2002; Venance et al., 2004). A pioneering study showed a dye coupling between DA neurons of the SNc in vivo in adult rats (Grace and Bunney, 1983b), suggesting the existence of an intercellular communication. Recent studies report the expression of connexins $(\mathrm{Cx})$ in DA neurons in juvenile rats (Leung et al., 2002) but also an absence of dye coupling in these cells (Lin et al., 2003). Thus, gap junctional communication between DA neurons remains to be clarified. Furthermore, direct evidence of functional electrical synapses between DA neurons is still lacking.

Using tracer and electrical coupling experiments on rat brain slices, we directly measured electrical coupling for the first time between DA neurons of the SNc. DA neurons of SNc were found to be mainly interconnected by symmetrical electrical synapses that display low-pass filtering properties. Although no significant spontaneous synchronous activity was observed between pairs of DA neurons, electrical synapses were shown to modulate the firing frequency of electrically coupled DA neurons.

\section{Materials and Methods}

Electrophysiological recordings. Whole-cell recordings were done in coronal Sprague Dawley rat [postnatal day 5 (P5) to P25] brain slices (350 $\mu \mathrm{m}$ thick). All experiments were performed in accordance with the local ethical committee and European Union guidelines (directive 86/609/European Economic Community). Whole-cell recordings were made using borosilicate glass pipettes of 4-7 M $\Omega$ resistance containing the following (in $\mathrm{mm}$ ): $105 \mathrm{~K}$-gluconate, $30 \mathrm{KCl}, 10 \mathrm{HEPES}, 10$ phosphocreatine, 4 ATP-Mg, 0.3 GTP-Na, 0.3 EGTA (adjusted to pH 7.35 with KOH). In 
experiments using $\mathrm{Cs}^{+}$-based intracellular solution, the composition was identical, except that $\mathrm{K}$-gluconate and $\mathrm{KCl}$ were replaced by Csgluconate and $\mathrm{CsCl}$, respectively ( $\mathrm{pH}$ was adjusted to 7.35 with $\mathrm{CsOH}$ ). The composition of the extracellular solution was as follows (in mM): 125 $\mathrm{NaCl}, 2.5 \mathrm{KCl}, 25$ glucose, $25 \mathrm{NaHCO}_{3}, 1.25 \mathrm{NaH}_{2} \mathrm{PO}_{4}, 2 \mathrm{CaCl}_{2}, 1 \mathrm{MgCl}_{2}$, $10 \mu \mathrm{M}$ pyruvic acid (sodium salt), and $10 \mu \mathrm{M}$ 6,7-dinitroquinoxaline-2,3dione (DNQX), $10 \mu \mathrm{m}$ bicuculline methiodide, and $4 \mu \mathrm{M}$ (+)-5-methyl10,11-dihydro-5H-dibenzo [a,d] cyclohepten-5,10-imine maleate (MK801 ) bubbled with $95 \% \mathrm{O}_{2}$ and $5 \% \mathrm{CO}_{2}$. All whole-cell recordings were performed at $34^{\circ} \mathrm{C}$ using a temperature control system (Bioptechs DTC3; Bioptechs, Butler, PA). Signals were amplified using an EPC9-2 amplifier (HEKA Elektronik, Lambrecht, Germany). Current-clamp recordings were filtered at $2.5 \mathrm{kHz}$ and sampled at $5 \mathrm{kHz}$, whereas voltageclamp recordings were filtered at $5 \mathrm{kHz}$ and sampled at $10 \mathrm{kHz}$ using the program Pulse-8.50 (HEKA Elektronik). Series resistance compensation was set to $75-90 \%$ in whole-cell configuration. Liquid junction potential error was calculated $(-13.6 \mathrm{mV})$ according to the formula by Barry and Lynch (1991). The distance between two simultaneously recorded DA neurons was in the range of 10-50 $\mu \mathrm{m}$. Except for DNQX (Tocris Cookson, Fischer Scientific, Illkirch, France), all chemicals (bicuculline methiodide, MK-801, carbenoxolone) were from Sigma (St. Quentin Fallavier, France).

Data analysis. Off-line analysis was performed using PulseFit-8.50 (HEKA Elektronik) and Igor Pro (Wavemetrics, Lake Oswego, OR). All results were expressed as mean \pm SEM, and statistical significance was assessed using the Student's $t$ test, or the nonparametric Mann-Whitney test when appropriate, at the significance level $p<0.05$. Action potential (AP) threshold was measured as follows: DA neurons were first clamped to $-60 \mathrm{mV}$, and successive depolarization steps (10 pA steps) were applied until the first AP, on which the threshold was then measured (see Fig. $1 A)$. Input resistance $\left(R_{\text {input }}\right)$ was calculated from voltage responses obtained after injecting a hyperpolarizing current $(-10 \mathrm{pA} ; 1 \mathrm{sec}$ duration). "Sag" amplitude was measured from voltage responses obtained after injecting a hyperpolarizing current $(-90 \mathrm{pA} ; 1$ sec duration; cell held previously at $-60 \mathrm{mV}$ ) between the potential at sag peak (see Fig. 1, $\bigcirc)$ and the potential at steady state (see Fig. 1, ). Spike duration was measured between the onset of the spike and the equipotential point during the repolarization phase. Fast afterhyperpolarization amplitude was taken between this last point and the minimum of the afterhyperpolarization. Coupling coefficient (e.g., $k_{12}$ ) was calculated as the ratio of voltage responses of the postsynaptic (receiving) cell (here, cell 2) to the presynaptic (stimulated) cell (here, cell 1). For hyperpolarizing or depolarizing pulses, the amplitude of the presynaptic voltage response was measured between the holding membrane potential and the steady state after the sag (estimated $450 \mathrm{msec}$ after stimulus onset), or the threshold of the first spike, respectively, for each stimulus. By convention, $k_{12}$ was chosen as the higher $k$ (i.e., the cell with the higher $k$ to the other cell was chosen as cell 1$)$. Using this convention, $\mathrm{K}$ ratio was defined as $k_{12} / k_{21}$ and $R_{\text {input }}$ ratio as $R_{22} / R_{11}$. Junctional conductance $(\mathrm{Gj})$ was estimated as follows: $\mathrm{Gj}_{12}=k_{12} /\left(R_{22}-R_{11} k_{12}{ }^{2}\right)$. Rectification of electrical synapses was investigated by measuring $\mathrm{Gj}$ for depolarizing and hyperpolarizing stimuli in each direction of coupling ( $\mathrm{Gj}$ for depolarizing stimuli, $\mathrm{Gj}_{\mathrm{d} 12}$ and $\mathrm{Gj}_{\mathrm{d} 21}$; $\mathrm{Gj}$ for hyperpolarizing stimuli, $\mathrm{Gj}_{\mathrm{h} 12}$ and $\mathrm{Gj}_{\mathrm{h} 21}$ ) and then comparing ratios of $\mathrm{Gj}_{\mathrm{d} 12} / \mathrm{Gj}_{\mathrm{d} 21}$ and $\mathrm{Gj}_{\mathrm{h} 12} / \mathrm{Gj}_{\mathrm{h} 21}$. When sinusoidal stimuli were used, 50-100 responses were averaged and subjected to a fast Fourier transform to confirm that the major frequency of the response was the frequency of the applied stimulus.

The relationship between the activity of each pair of cells was quantified using the following procedure. First, recordings were encoded into binary sequences: for each time point, subthreshold activity was encoded as 0 and spikes as 1 . Second, mutual information between binary sequences $X$ and $Y$ of the cell pairs (i.e., the predictability of the activity of a cell from knowing the activity of the coupled cell) was computed as $I(X: Y)=H(X)+H(Y)-H(X, Y)$, where $H(X)$ is the entropy of the recording $X$, and $H(X, Y)$ is the joint entropy of the recordings $X$ and $Y$ (Shannon, 1948). Entropy of the recording $X$ is given by the following:

$$
H(X)=-\sum_{s(X)} p[s(X)] \times \log p[s(X)]
$$

where $s(X)$ and $p[s(X)]$ denote the state of recording $X$ (i.e., 0 for subthreshold activity and 1 for spikes) and the probability of $s(X)$, respectively. Similarly, joint entropy of simultaneous recordings $X$ and $Y$ is given by the following:

$$
H(X, Y)=-\sum_{s(X)} \sum_{s(Y)} p[s(X), s(Y)] \times \log p[s(X), s(Y)] .
$$

Finally, statistical significance of the mutual information measurement was tested using a bootstrap method. Namely, one of the binary sequences from each pair was taken as a template, and the other was used to generate surrogate data by randomization of real interspike intervals. The correlation between the cells was considered significant when the mutual information computed between the "real" pair of cells was higher than that computed from the set of 500 surrogate pairs (statistical threshold, 5\%).

Biocytin filling and histochemistry. Biocytin ( $5 \mathrm{mg} / \mathrm{ml}$; Sigma) was dissolved in the pipette solution, and cells were filled during at least $45 \mathrm{~min}$ of recording (performed at room temperature). Subsequently, slices were fixed overnight in $2 \%$ paraformaldehyde at $4^{\circ} \mathrm{C}$. Biocytin-filled cells were visualized using the avidin-HRP reaction (ABC Elite peroxidase kit; Vector Laboratories, Burlingame, CA) according to the instructions of the manufacturer.

\section{Results}

SNc DA neurons $(n=287)$ recorded from coronal rat brain slices were distinguished from fast-spiking neurons of the SNc and GABAergic output neurons of the substantia nigra pars reticulata by their specific electrophysiological features (Grace and Bunney, 1983a; Kita et al., 1986). Indeed, DA neurons display characteristic passive membrane properties and spiking pattern (Fig. $1 A, B)$, including a pronounced sag ( $I_{\mathrm{h}}$ current activation) $(-21.1 \pm 2.0 \mathrm{mV})$ during hyperpolarization steps $(-90 \mathrm{pA})$ followed by a depolarizing rebound $(11.3 \pm 1.0 \mathrm{mV})$ at the stimulus offset, a depolarized action potential threshold $(-36.4 \pm 0.4$ $\mathrm{mV})$, a long spike duration $(5.6 \pm 0.1 \mathrm{msec})$, a large fast afterhyperpolarization amplitude $(18.7 \pm 0.8 \mathrm{mV})$, and finally a slow spontaneous regular spiking activity $(3.7 \pm 0.4 \mathrm{~Hz}$ ) (as measured from 39 DA neurons).

\section{Tracer coupling between dopaminergic neurons}

Tracer coupling between DA neurons was assessed within the first postnatal month (P5-P25). Electrophysiologically identified DA neurons $(n=71)$ were successfully filled with biocytin contained in the patch pipette (Fig. $1 C, D$ ). From P5 to P10, coupling incidence was $40 \%(n=20)$, with a mean of $2.8 \pm 1.4$ neurons to which tracer spreads per injected cell, but tracer coupling was no longer observed between P10 and P15 $(n=27)$. Surprisingly, between P15 and P25, 17\% of DA cells $(n=24)$ were found coupled with one to three surrounding neurons (Fig. $1 D$ ). Thus, tracer coupling appears over two separate periods, suggesting a developmental regulation (variations of tracer coupling were found to be significant assessed by Fischer's exact test). Neither somato-somatic tracer coupling between DA neurons nor neuroglial coupling was detected.

\section{Electrical coupling between dopaminergic neurons}

The existence of electrical synapses between DA neurons was investigated by dual whole-cell patch-clamp recordings (at $32^{\circ} \mathrm{C}$ ) from 66 DA neuron pairs during time periods when tracer coupling was observed.

In P7-P10 animals ( $n=51$ DA neuron pairs), most of DA neuron pairs were electrically coupled. Indeed, during injection of current or voltage in the presynaptic cell (stimulated cell), an electrotonic response was detected in the postsynaptic cell (re- 

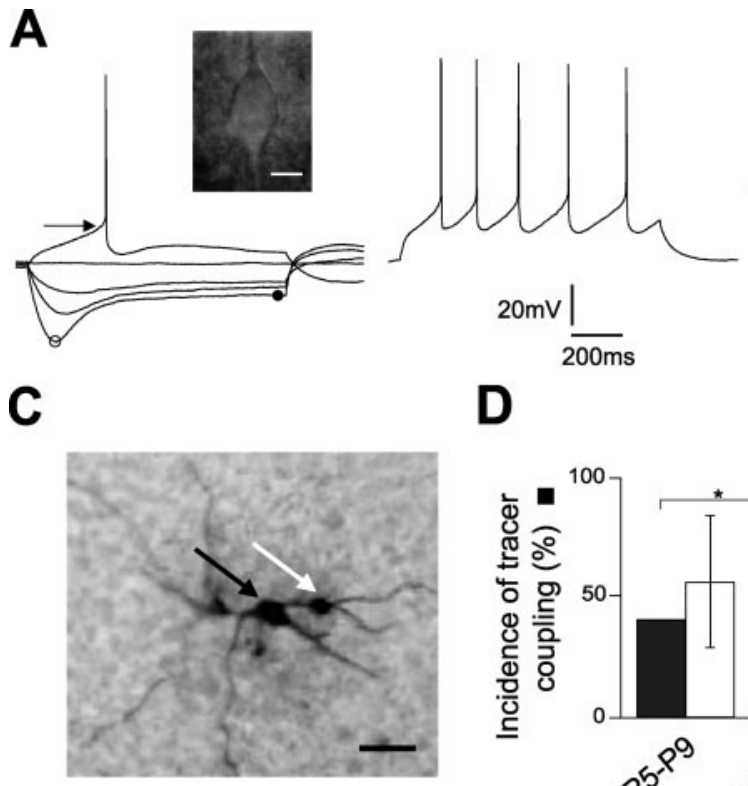

$20 \mathrm{mV} \mid$

B

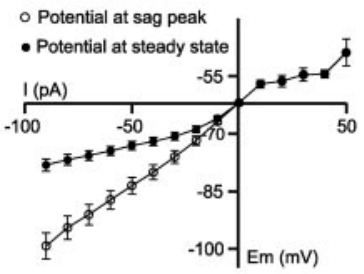

D

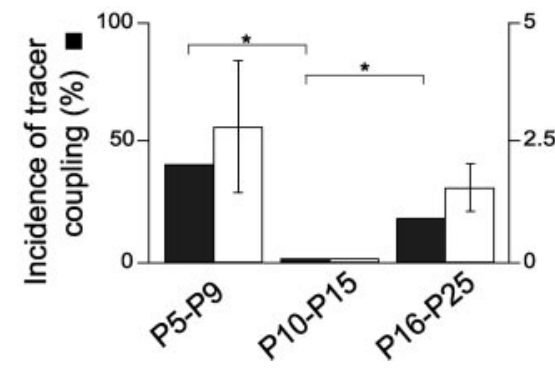

Figure 1. Electrophysiological characterization of DA neurons and tracer coupling between DA neurons. $A$, Responses of a DA neuron to current injections $[-90,-60,-30,0,+30 \mathrm{pA}$, left panel; $+70 \mathrm{pA}$, right panel (same cell); holding potential was $-60 \mathrm{mV}$, with $-50.7 \mathrm{pA}$ injected current]. The arrow represents where the AP threshold was estimated (at the point where the rate of rise accelerates sharply). Inset, Infrared image of an electrophysiologically identified DA neuron. Scale bar, $20 \mu \mathrm{m}$. B, Sag peak $(\bigcirc)$ and steady state $(-) I-V$ relationship (mean of 21 DA neurons). C, Tracer coupling between SNc neurons in a coronal P17 rat brain slice. The electrophysiologically identified DA neuron (black arrow) was filled with a tracer (biocytin) that diffused into another neuron (white arrow) through gap junctions. Scale bar, $100 \mu \mathrm{m}$. D, Evolution of incidence of tracer coupling and number of coupled neurons during postnatal development. Fischer's exact test; $* p<0.05$.

\section{Current Clamp}

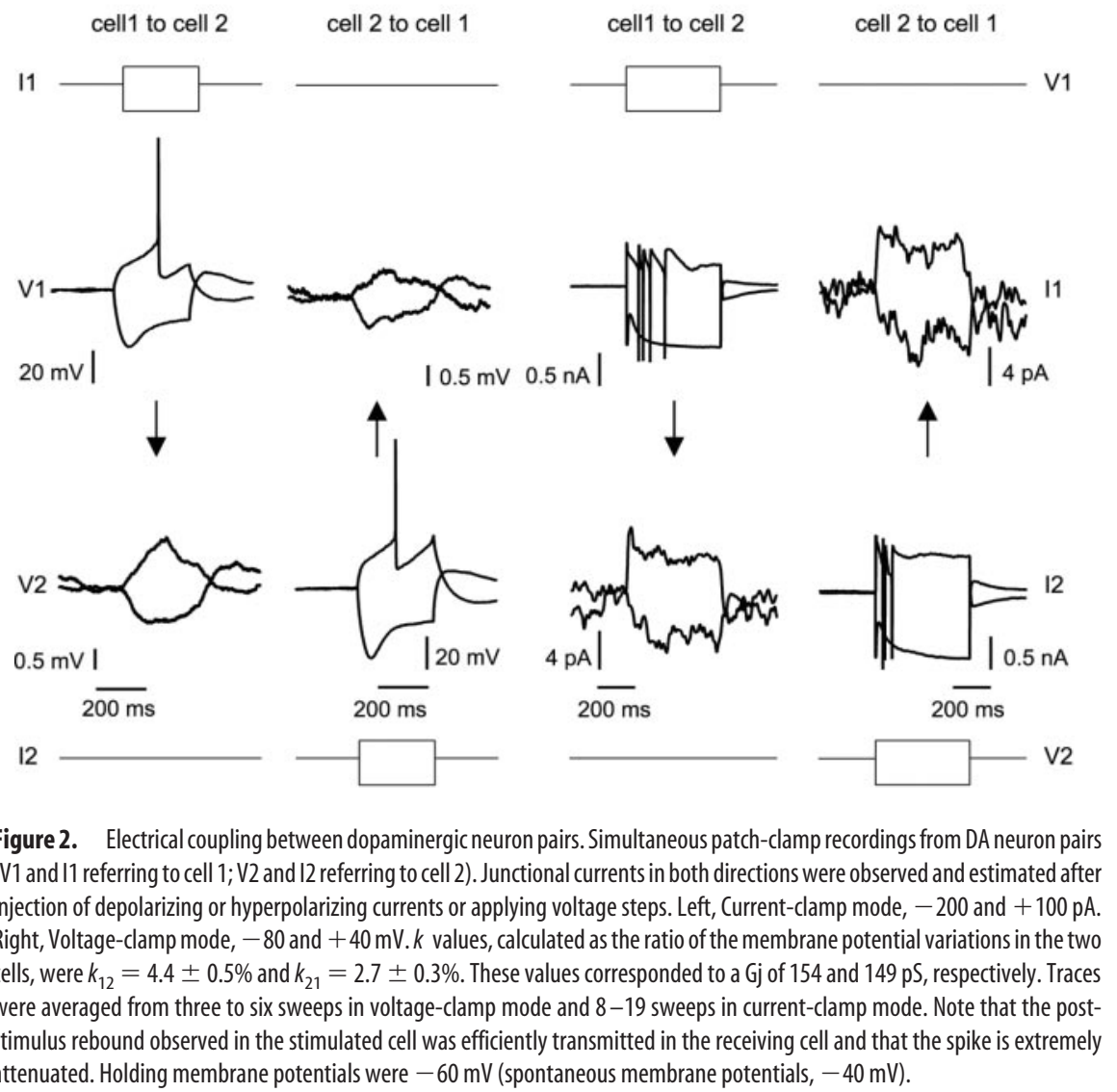

ceiving cell) in $96 \%$ of DA neuron pairs (Fig. 2). It is worth noting that membrane potential rebounds after hyperpolarizing or depolarizing steps were efficiently electrotonically transmitted (Fig. 2). The mean value of the coupling coefficient $(k)$ of electrically coupled DA neuron pairs $(n=49)$ was $2.3 \pm 0.2 \%$ (ranging from 1.4 to $4.3 \%$ ) corresponding to a junctional conductance value $(\mathrm{Gj})$ of $86.2 \pm 7.0 \mathrm{pS}$ (from 22.8 to $170.8 \mathrm{pS}$ ). Attempts were made to increase $k$ by reducing $\mathrm{K}^{+}$conductances (intracellular $\mathrm{K}^{+}$replaced by $\mathrm{Cs}^{+}$) and $\mathrm{Ca}^{2+}$ buffering (10 mM intracellular EGTA added). These conditions (see Fig. $4, \bigcirc)$ did not significantly change the mean $k(2.1 \pm 0.3 \% ; n=4)$ and $\mathrm{Gj}(79.2 \pm$ $25.1 \mathrm{pS} ; n=4)$ when compared with control conditions (see Fig. 4, $)$ ). In addition, input resistance $\left(R_{\text {input }}\right)$ was not significantly different ( $307.6 \pm 36.6 \mathrm{M} \Omega, n=8$, vs $298.6 \pm 2.3 \mathrm{M} \Omega, n=46$, in control condition), denoting a weak contribution of potassium conductances in these cells.

When P17-P21 rats ( $n=15$ DA neuron pairs) were used, coupling incidence decreased to $20 \%$ of the recorded pairs. In these conditions, $k(1.9 \pm 0.3 \%$; ranging from 1.4 to $2.2 \%)$ and $\mathrm{Gj}(60.3 \pm 0.7 \mathrm{pS}$; ranging from 59.1 to $61.7 \mathrm{pS}$ ) values were not significantly different from those measured in P7-P10 rats.

Attempts were made to pharmacologically block gap junctional communication between DA neurons. Transjunctional currents were totally abolished in the presence of $2 \mathrm{~mm}$ octanol $(n=4$; data not shown). However, unsaturated alcohols (heptanol and octanol) and volatile anesthetics (halothane) known to be efficient uncoupling agents also have several nonspecific effects (Venance et al., 1998; Rozental et al., 2001). Consequently, a rather specific uncoupling agent, carbenoxolone (Davidson et al., 1986) (but see Rouach et al., 2003, for inhibitory effect on spontaneous activity) was chosen. Carbenoxolone $(200 \mu \mathrm{M})$ totally abolished junctional current in three of four cell pairs (Fig. 3). No significant change in $R_{\text {input }}$ between control and carbenoxolone conditions was observed. Indeed, the average value of input conductances $(3723.2 \pm 0.2$ pS) was much larger than the junctional conductance values $(86.2 \pm 7.0 \mathrm{pS})$.

Equality of $k$ for both directions of electrical coupling was analyzed in 28 cell pairs (Fig. 4). Most DA neuron pairs $(82 \%)$ displayed equal $k$, whereas five DA cell pairs showed significantly different $k$ (ranging from 1.6- to 2.2-fold) (Fig. 4B). The relative values of the two $R_{\text {input }}$ of the cells were then investigated. First, Gj was 


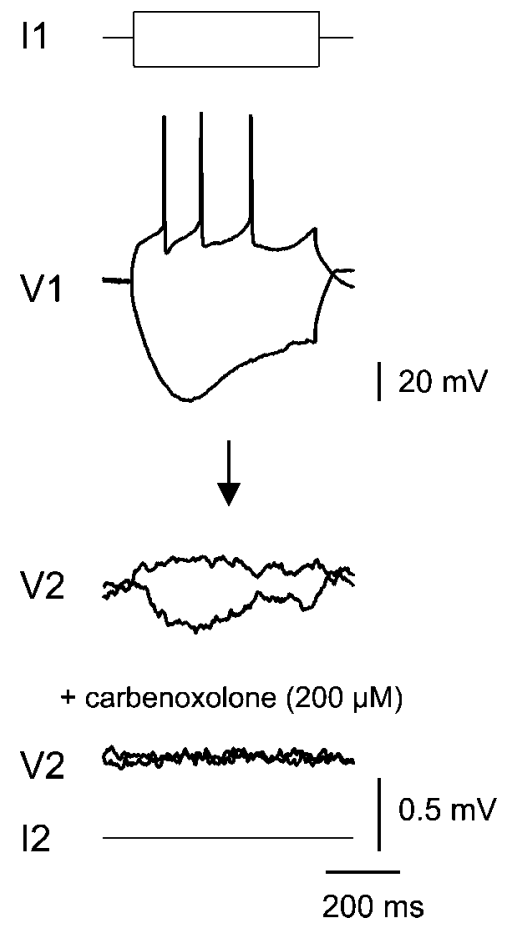

Figure 3. Inhibition of junctional currents by carbenoxolone $(200 \mu \mathrm{M})$. Junctional currents were totally abolished after $5 \mathrm{~min}$ of bath application of carbenoxolone $200 \mu \mathrm{m}$ (V2 is the average of 15 traces). Voltage traces were obtained from coupled DA neurons (P9), both held at $-60 \mathrm{mV}$. The $k$ value before carbenoxolone application was $1.0 \pm 0.1 \%$. Note that $\mathrm{V} 2$ baseline in the presence of carbenoxolone appears less noisy than V2 in control conditions. This could be attributable to an unspecific effect of carbenoxolone on spontaneous synaptic activity, as reported previously by Rouach et al. (2003).

estimated, and a distribution similar to the $k$ plot was obtained (Fig. 4C). Second, the ratio of the higher to the lower $k$ (K ratio) was plotted against the ratio of the $R_{\text {input }}$ of the postsynaptic to the presynaptic cell in the direction of the higher $k\left(R_{\text {input }}\right.$ ratio) (Fig. $4 D)$. In their great majority, cell pairs displayed a symmetric $\mathrm{Gj}$.

No evidence of rectification was found when successive hyperpolarizing and depolarizing current steps were applied. Indeed, we measured $\mathrm{Gj}$ for depolarizing and hyperpolarizing stimuli in each direction of coupling $\left(\mathrm{Gj}\right.$ for depolarizing stimuli, $\mathrm{Gj}_{\mathrm{d} 12}$ and $\mathrm{Gj}_{\mathrm{d} 21} ; \mathrm{Gj}$ for hyperpolarizing stimuli, $\mathrm{Gj}_{\mathrm{h} 12}$ and $\mathrm{Gj}_{\mathrm{h} 21}$ ) and then compared ratios of $\mathrm{Gj}_{\mathrm{d}_{12}} / \mathrm{Gj}_{\mathrm{d} 21}$ and $\mathrm{Gj}_{\mathrm{h} 12} / \mathrm{Gj}_{\mathrm{h} 21}(n=11$ electrically coupled DA neuron pairs) (Fig. $4 E$ ). The weak difference between $\mathrm{Gj}_{\mathrm{d}}$ ratio and $\mathrm{Gj}_{\mathrm{h}}$ ratio indicated that the investigated electrical synapses were mainly nonrectifying.

\section{Electrical synapses between dopaminergic neurons act as a low-pass filter}

Brain electrical synapses described thus far display low-pass filter properties (Galarreta and Hestrin, 2001). To determine whether electrical synapses between DA neurons exhibit such a characteristic, sinusoidal stimuli of different frequencies $(1-50 \mathrm{~Hz})$ were applied to the presynaptic neuron (Fig. $5 A-C$ ). Electrically coupled DA neuron pairs (P7-P10; $n=30)$ exhibited low-pass filtering properties, namely a strong attenuation (3.0-fold between 2 and $10 \mathrm{~Hz}$ ) in the $k$ value and an increasing phase lag (3.1-fold between 2 and $10 \mathrm{~Hz}$ ) for higher frequencies. Transmission of spikes through gap junctions appears to be a physiological illustration of these low-pass filtering properties. Indeed, in electrically coupled DA neuron pairs, presynaptic action potentials can generate electrotonic postsynaptic events, named spikelets (Ben-
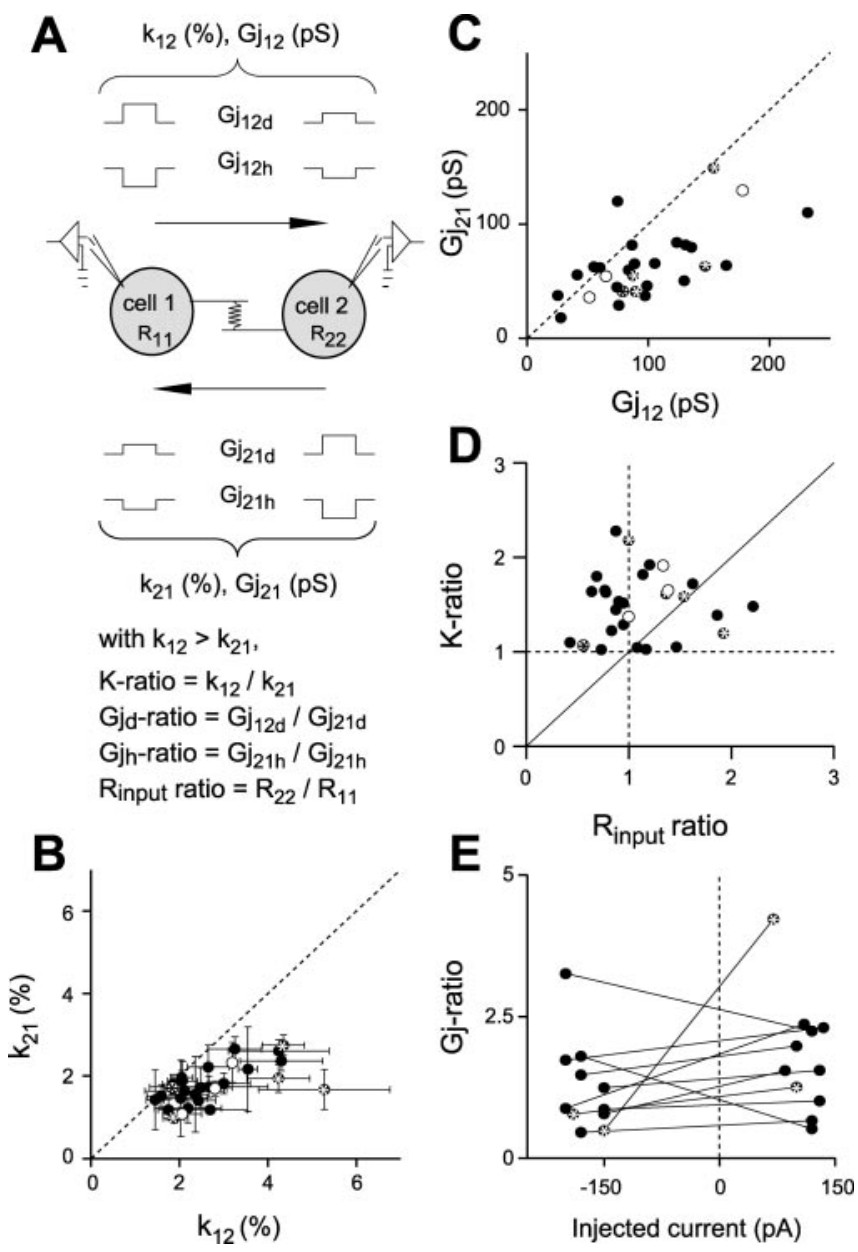

Figure 4. Characteristics of electrical synapses between dopaminergic neurons. $A$, Scheme of the protocol procedure with definition of parameters used in $B-E$. $B, C$, Comparison of $k(B)$ and $\mathrm{Gj}(C)$ in both directions of coupling for each cell pair $(n=28)$ indicates, for most (82\%) DA neuron pairs, a lack of significant rectification. $k$ was plotted with $k_{12}$ being the higher $k$, and $G$ j values were then plotted accordingly. Dashed lines indicate identical $k$ or $\mathrm{Gj}$ in both directions, representing a symmetrical coupling. D, Relationship between apparent rectification ( $\mathrm{K}$ ratio) and $R_{\text {input }}$ ratio. For each $\mathrm{DA}$ neuron pair, the $\mathrm{K}$ ratio is the ratio of the higher $k$ to lower $k$ (i.e., $\mathrm{K}$ ratio $\left.=k_{12} / k_{21}\right)$. The corresponding $R_{\text {input }}$ ratio is the ratio between the $R_{\text {input }}$ in the postsynaptic DA neuron versus the $R_{\text {input }}$ of the presynaptic cell in the direction of the larger $k$ (i.e., $R_{\text {input }}$ ratio $=R_{22} / R_{11}$ ). The continuous diagonal line represents values expected for cell pairs connected by symmetrical $\mathrm{Gj}$ (with asymmetrical $k$ and $R_{\text {input }}$ ). Vertical and horizontal dashed lines represent values expected for cell pairs with $R_{\text {input }}$ and $k$ symmetrical, respectively. The mean $\mathrm{K}$ ratio was $1.52 \pm 0.07$. Recordings with $\mathrm{Cs}^{+}$-based intracellular solution $(n=4 ; \bigcirc)$ did not differ significantly from those obtained in normal conditions $(n=24 ; O)$. E, Relationship between $\mathrm{Gj}$ ratio and injected current in $11 \mathrm{DA}$ neuron pairs $\left(\mathrm{Gj}_{\mathrm{h}}\right.$ ratios and $\mathrm{Gj} \mathrm{j}_{\mathrm{d}}$ ratios are plotted on the left and right sides of the vertical dashed line, respectively). Except for one cell pair (also displaying an asymmetrical coupling), DA electrical synapses appeared to be mainly nonrectifying. * indicates pairs presenting a significantly asymmetrical coupling.

nett, 1997; Galarreta and Hestrin, 2001). Such events should be highly dependent on $k$ values, electrotonic distance of the coupling site, and neuronal architecture. Among DA neuron pairs, spikelets were only observed in an electrically coupled pair presenting one of the highest $k(3.5 \pm 0.8 \%)$ values (Fig. $5 D)$. In this cell pair, spikelets displayed a mean peak amplitude value of $0.31 \pm 0.02 \mathrm{mV}(n=14)$ corresponding to a $k$ (ratio of spikelet to presynaptic spike amplitudes) of $0.52 \pm 0.03 \%$. Spikelets showed a latency (basis to basis) of $0.6 \pm 0.1 \mathrm{msec}$ (peak-to-peak latency, $2.6 \pm 0.3 \mathrm{msec}$ ), a rise time of $2.1 \pm 0.4 \mathrm{msec}$, and a decay time of $14.1 \pm 2.1 \mathrm{msec}(n=14)$. 
A $2 \mathrm{~Hz}$ $5 \mathrm{~Hz}$ $10 \mathrm{~Hz}$

11<smiles>CCCCCCC</smiles>
৩ DWOWL

V1
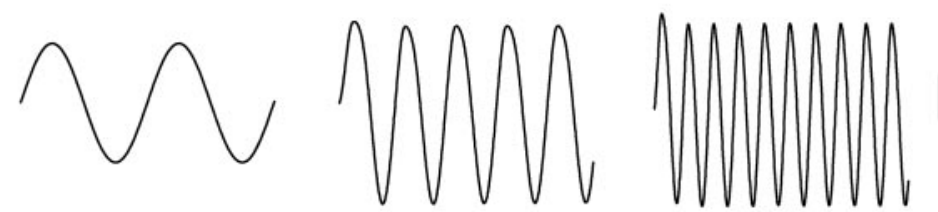

$10 \mathrm{mV}$ V2
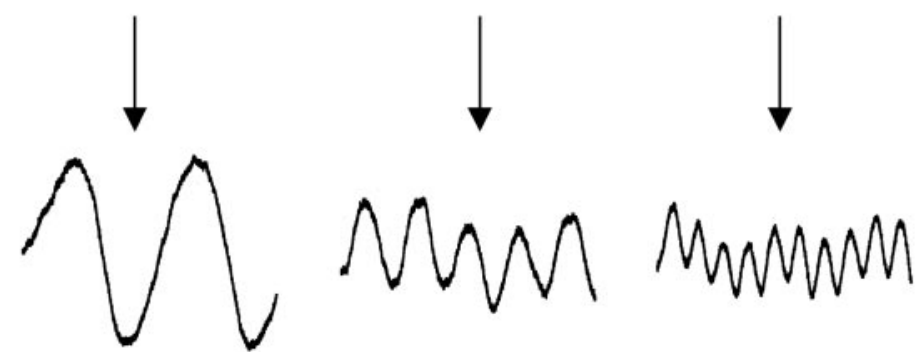

$0.4 \mathrm{mV}$

12

B
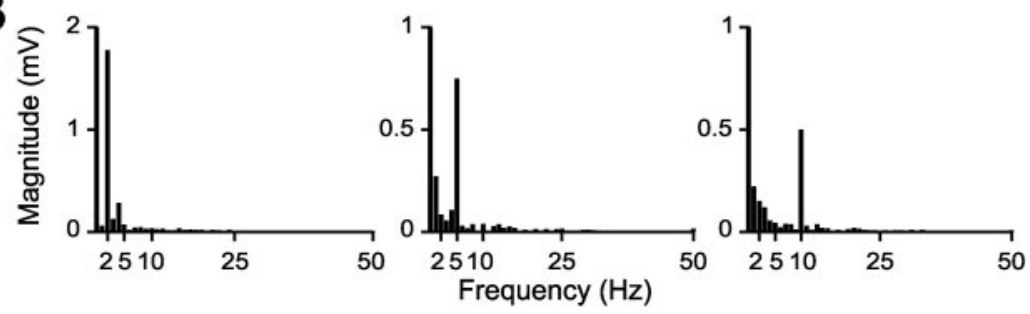

C
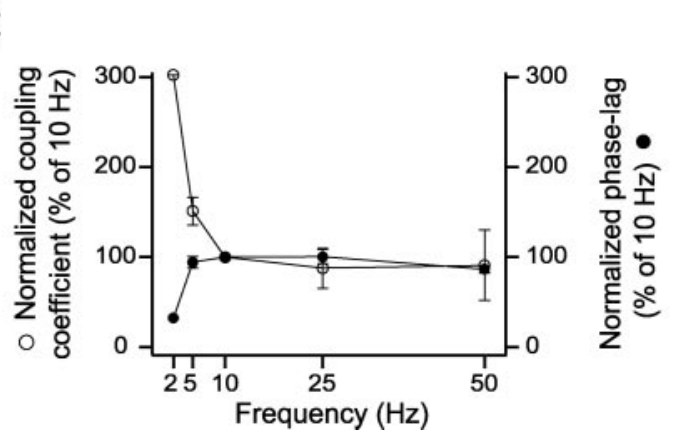

D

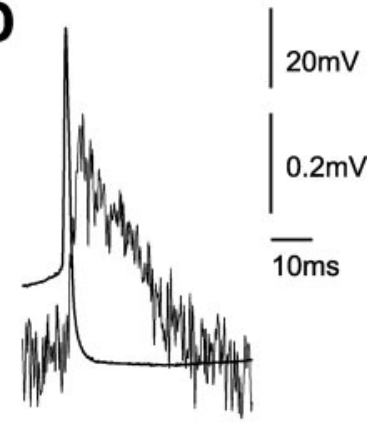

Figure 5. Electrical synapses between dopaminergic neurons act as low-pass filters. $A$, Subthreshold sinusoidal current injections (I1) (200 pA peak-to-peak amplitude at $2 \mathrm{~Hz}, 260 \mathrm{pA}$ at $5 \mathrm{~Hz}, 400 \mathrm{pA}$ at $10 \mathrm{~Hz}$ ) into cell 1 of an electrically coupled pair induced membrane potential oscillations in both cell 1 (V1) and cell 2 (V2) (averages of 50 traces). Mean $k$ value of this DA neuron pair was $3.5 \pm 0.8 \%$. B, Magnitude of the fast Fourier transform computed from traces shown in $A, \mathrm{~V} 2(\mathrm{bin}, 1 \mathrm{~Hz})$. The major frequency in the receiving cell is identical to the applied stimulating frequency $(A ; 1)$. C, Frequency dependency of $k(O)$ and phase $\operatorname{lag}(\mathbf{O})$. Values were normalized for each DA neuron pair to the $10 \mathrm{~Hz}$ and phase lag values $(n=19)$. Mean $\mathrm{k}$ at $10 \mathrm{~Hz}$ was $0.20 \pm 0.05 \%$. Mean phase lag at $10 \mathrm{~Hz}$ was $173 \pm 7^{\circ}$. Note that coupling coefficient decreases with increasing frequency of the sinusoidal oscillations associated with an increased phase lag. D, Spike transmission through electrical synapses between a pair of dopaminergic neurons. The attenuated transmission of presynaptic spikes (spikelets) is illustrated by superimposing the presynaptic spike over an induced spikelet recorded in the postsynaptic cell of a coupled DA neuron pair. Holding membrane potentials were $-60 \mathrm{mV}$.

Electrical coupling fails to synchronize spontaneous activity but efficiently modulates firing rate of coupled dopaminergic neurons

Because most DA neurons are tonically active, both in vitro and in vivo (Grace and Bunney, 1983a; Sanghera et al., 1984; Freeman et al., 1985; Kita et al., 1986), the impact of electrical coupling on spontaneous spiking activity was investigated. Among all recorded DA neurons, $94 \%$ were found to be tonically active in our conditions. First, to determine a possible synchronization in spontaneous firing between DA neurons (membrane potential, $-44.9 \pm 0.8 \mathrm{mV}$ when no current was injected; $n=62$ neurons), crosscorrelation analysis was performed on 31 P7-P10 DA neuron pairs (Fig. 6A). Summation of the 31 normalized crosscorrelograms did not reveal any correlation between pairs of DA neurons (Fig. $6 A a, A b)$. To objectify this result, we calculated the mutual information value in the 20 msec range of the suprathreshold activities for each pair of simultaneously recorded coupled DA neurons. Mutual information value was weak and did not significantly segregate from values calculated from surrogate data (obtained by random shuffling of interspike intervals) (Fig. 6Ac). Thus, coupled DA neuron activities did not show any significant, linear or nonlinear, functional correlation.

Finally, electrical synapses between DA neurons mediated an efficient modulation of spiking activity between electrically coupled neurons (Fig. 6B). To investigate the weight of electrical synapses on spiking activity, depolarizing or hyperpolarizing pulses were applied in one cell, and the effect on the action potential frequency of the postsynaptic cell was analyzed (Fig. $6 \mathrm{Ba}$ ). In $64 \%$ of DA neuron pairs (P7$\mathrm{P} 10 ; n=11)$, the firing rate of the postsynaptic neuron was significantly decreased $(-6.6 \pm 2.0 \% ; n=7)$ during the injection of a hyperpolarizing current into the presynaptic cell. Similarly, in $73 \%$ of the tested DA neuron pairs $(n=11)$, a significant increase in the spontaneous firing rate of the postsynaptic cell $(+5.2 \pm 1.7 \%$; $n=8$ ) was observed when a depolarizing current was applied to the presynaptic cell (Fig. 6Bb).

\section{Discussion}

Our study demonstrates that nigrostriatal DA neurons are connected by functional electrical synapses. Spontaneously active DA neurons in coupled pairs do not display significant synchronous activity. Nevertheless, membrane potential variations of one of these coupled DA neurons efficiently modulate the firing frequency of the coupled DA neuron.
Tracer coupling between dopaminergic neurons

A pioneering in vivo study by Grace and Bunney (1983b) first reported dye coupling between DA neurons in adult rats. Our results extend this observation because tracer coupling could be demonstrated in juvenile rat brain slices. Although tracer cou- 
pling was observed in P5-P10 and P15P25 animals, surprisingly, tracer coupling was absent between P10 and P15. Two hypotheses could explain such observation: either an absence of junctional channels linking DA neurons or junctional channels are no longer permeable to biocytin. Such lack of tracer coupling at this time could explain the absence of dye coupling reported by Lin et al. (2003) in the same neurons (besides the difference of slice angle, horizontal vs coronal).

This temporary lack of tracer coupling takes place during a critical period of DA cell maturation. Indeed, an apoptotic peak occurs between P12 and P16, interpreted as a target-dependent selection of DA neurons (Marti et al., 1997; Burke, 2003). This temporary absence of intercellular communication may have a protective effect by preventing the propagation of death signals between preapoptotic and nonapoptotic DA neurons (Lin et al., 1998; Andrade-Rozental et al., 2000).

The tracer coupling between DA neurons suggests the diffusion and propagation of small molecules, such as energy metabolites, amino-acids, and second messengers between these cells (Harris, 2001). As shown in the peripheral neuroendocrine system, second messenger diffusion through gap junctions plays a key role in signaling and synchronization (Saez et al., 2003). Therefore, metabolic coupling between DA neurons may contribute to the formation of neuronal ensembles within the DA cell population.

The modalities of a metabolic coupling within and between subpopulations of DA neurons remain to be explored. Based on their electrophysiological characteristics (Gu et al., 1992; Hajos and Greenfield, 1993; Neuhoff et al., 2002), connectivity (Fallon and Moore, 1978; Grace and Onn, 1989; Gauthier et al., 1999), receptor subtypes (Chen et al., 2001), and peptide expression (Seroogy et al., 1988), DA neurons are heterogeneous. Depending on their functional states (open or closed, respectively), gap junction channels may attenuate or unveil the heterogeneity between subpopulations of DA cells. According to results from calcium-signaling experiments, such a role of gap junction channels has already been demonstrated in subpopulations of striatal astrocytes in culture (Venance et al., 1998).

\section{Electrical coupling between dopaminergic neurons}

DA neurons are connected by functional electrical synapses. Electrical coupling had a high incidence in P7-P10 rats, decreasing thereafter but still present in $20 \%$ of the recorded DA cells in P17-P21 rats. Electrical coupling between DA neurons was bidirectional and mainly symmetrical like most other electrical synapses. Electrical synapses between DA neurons act as low-pass filters, a functional property shared also by all electrical synapses described so far in the CNS of mammals (Galarreta and Hestrin, (b)

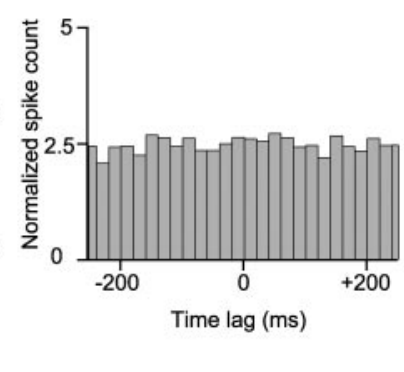

(b)
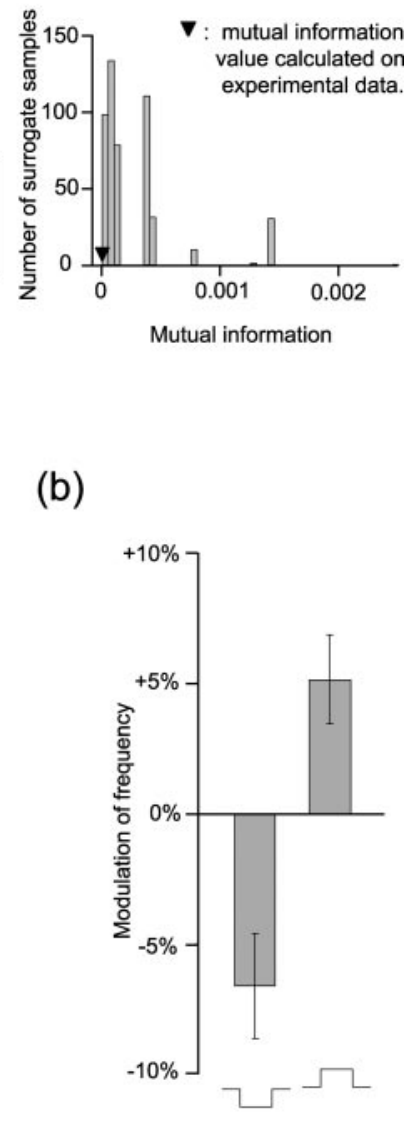

Figure 6. Spontaneous firing activities of electrically coupled dopaminergic neurons are interdependent but not synchronous. the DA neurons shown in a using a bootstrap method (see Materials and Methods). Position of the experimental mutual information value (arrowhead) calculated from original data did not segregate from the distribution of the mutual information 作 spontaneous tonical activity, induces a decrease and an increase in the spontaneous firing rate of cell 2 (V2), respectively. $B b$, Mean change of the spontaneous firing rate of the receiving cells for hyperpolarizing pulses ( $-200 \mathrm{pA} ; n=7 \mathrm{DA}$ neuron pairs) and depolarizing pulses ( $+70 \mathrm{pA} ; n=8 \mathrm{DA}$ neuron pairs) applied in the stimulated cells.

2001; Bennett and Zukin, 2004). Indeed, fast events such as spikes were greatly attenuated or even not detected in the postsynaptic cell, whereas events with slow kinetics such as the sag and the posthyperpolarization rebound were efficiently transmitted. In DA neurons, these low-pass filtering properties of electrical synapses were more pronounced than those described for electrical synapses of neocortical, thalamic, or retinal GABAergic interneurons (Galarreta and Hestrin, 1999; Landisman et al., 2002; Meyer et al., 2002; Veruki and Hartveit, 2002).

\section{Functional implications}

The activity of DA neurons is regulated by the nigro-striatonigral feedback loop (Bunney and Achajanian, 1976) and, locally, by dopamine released from dendrites (Cheramy et al., 1981) through its inhibitory effect via DA autoreceptors (Groves et al., 1975; Skirboll et al., 1979; Pucak and Grace, 1994). According to our results, the depolarization of a DA cell can increase the spon- 
taneous firing frequency of the electrically coupled neuron despite the expected hyperpolarization resulting from the action of dendritically released dopamine on DA autoreceptors. Electrical synapses thus appear to have a greater impact than chemical interactions in fast communication between DA neurons. However, determination of the respective localizations (segregation or not) of electrical synapses and chemical interactions is necessary to understand their interplay and respective weight.

DA neurons display two modes of activity (tonic and phasic) resulting in different amounts of dopamine released in the striatum (Gonon, 1988). The tonic discharge, associated with a low but constant release of dopamine, supports a permanent tune-up of the striatal network, whereas phasic increases or decreases of discharge, resulting in important peaks or abrupt reductions in the transmitter release, correspond to a predictive reward value or to the lack of expected reinforcement, respectively (Schultz et al., 1997). In slices, DA neurons display only tonic activity without glutamatergic stimulation (Kita et al., 1986; Mereu et al., 1997). According to our results, this tonic activity was not significantly synchronized in electrically coupled DA neurons. However, the involvement of electrical coupling in synchronization processes is now well established for GABAergic interneuron networks (Fricker and Miles, 2001; Galarreta and Hestrin, 2001; LeBeau et al., 2003; Bennett and Zukin, 2004). In contrast to GABAergic interneurons that transmit fast information, DA neurons have wider action potentials ( 6 vs $0.5 \mathrm{msec}$ ), display a much lower firing frequency (3-4 vs $40-70 \mathrm{~Hz}$ ), and have a neuromodulatory role. These important kinetic and functional differences between the two types of cells could explain the apparent differences in the role of electrical coupling in these cells. Indeed, the lack of synchronization between tonically active DA neurons could be essential for a constant and nonpulsatile striatal dopamine release.

Nevertheless, according to the mathematical models of DA neuron pairs performed by Komendantov and Canavier (2002), in which NMDA receptor-mediated excitatory inputs are taken into account (mimicking an in vivo context), electrical coupling should promote synchronous bursting activity. This prediction is particularly promising because synchronization under NMDA stimulation is expected especially for weak electrical coupling (in the range of $\mathrm{Gj}$ estimated from our study). Thus, investigation of synchronization under NMDA-mediated stimulation remains to be performed because the expected synchronization of subsequent dopamine peaks in distinct striatal areas could have important functional consequences such as the linkage of rewardrelated information concerning different behavioral aspects in which the nigrostriatal pathway is involved. Still, synchronization may involve more complex processes, because an in vivo study by Morris et al. (2004) reports that only $27 \%$ of DA neurons display a synchronous activity.

\section{References}

Andrade-Rozental AF, Rozental R, Hopperstad MG, Wu JK, Vrionis FD, Spray DC (2000) Gap junctions: the "kiss of death" and the "kiss of life". Brain Res Brain Res Rev 32:308-315.

Barry PH, Lynch JW (1991) Liquid junction potentials and small cell effects in patch clamp analysis. J Membr Biol 121:101-117.

Bennett MV (1997) Gap junctions as electrical synapses. J Neurocytol 26:349-366.

Bennett MV, Zukin RS (2004) Electrical coupling and neuronal synchronization in the mammalian brain. Neuron 41:495-511.

Bunney BS, Achajanian GK (1976) d-Amphetamine-induced inhibition of central dopaminergic neurons: mediation by a striato-nigral feedback pathway. Science 192:391-393.
Burke RE (2003) Postnatal developmental programmed cell death in dopamine neurons. Ann NY Acad Sci 991:69-79.

Chen LW, Wei LC, Lang B, Ju G, Chan YS (2001) Differential expression of AMPA receptor subunits in dopamine neurons of the rat brain: a double immunocytochemical study. Neuroscience 106:149-160.

Cheramy A, Leviel V, Glowinski J (1981) Dendritic release of dopamine in the substantia nigra. Nature 289:537-542.

Christie MJ, Williams JT, North RA (1989) Electrical coupling synchronizes subthreshold activity in locus coeruleus neurons in vitro from neonatal rats. J Neurosci 9:3584-3589.

Davidson JS, Baumgarten IM, Harley EH (1986) Reversible inhibition of intercellular junctional communication by glycyrrhetinic acid. Biochem Biophys Res Commun 134:29-36.

Devor A, Yarom Y (2002) Electrotonic coupling in the inferior olivary nucleus revealed by simultaneous double patch recordings. J Neurophysiol 87:3048-3058.

Fallon JH, Moore RY (1978) Catecholamine innervation of the basal forebrain. IV. Topography of the dopamine projection to the basal forebrain and neostriatum. J Comp Neurol 180:545-580.

Freeman AS, Meltzer LT, Bunney BS (1985) Firing properties of substantia nigra dopaminergic neurons in freely moving rats. Life Sci 36:1983-1994.

Fricker D, Miles R (2001) Interneurons, spike timing, and perception. Neuron 32:771-774.

Galarreta M, Hestrin S (1999) A network of fast-spiking cells in the neocortex connected by electrical synapses. Nature 402:72-75.

Galarreta M, Hestrin S (2001) Electrical synapses between GABA-releasing interneurons. Nat Rev Neurosci 2:425-433.

Gauthier J, Parent M, Levesque M, Parent A (1999) The axonal arborization of single nigrostriatal neurons in rats. Brain Res 834:228-232.

Gerfen CR (1992) The neostriatal mosaic: multiple levels of compartmental organization. Trends Neurosci 15:133-139.

Gibson JR, Beierlein M, Connors BW (1999) Two networks of electrically coupled inhibitory neurons in neocortex. Nature 402:75-79.

Gonon FG (1988) Nonlinear relationship between impulse flow and dopamine released by rat midbrain dopaminergic neurons as studied by in vivo electrochemistry. Neuroscience 24:19-28.

Grace AA, Bunney BS (1983a) Intracellular and extracellular electrophysiology of nigral dopaminergic neurons-1. Identification and characterization. Neuroscience 10:301-315.

Grace AA, Bunney BS (1983b) Intracellular and extracellular electrophysiology of nigral dopaminergic neurons-3. Evidence for electrotonic coupling. Neuroscience 10:333-348.

Grace AA, Onn SP (1989) Morphology and electrophysiological properties of immunocytochemically identified rat dopamine neurons recorded in vitro. J Neurosci 9:3463-3481.

Graybiel AM, Hirsch EC, Agid Y (1990) The nigrostriatal system in Parkinson's disease. Adv Neurol 53:17-29.

Groves PM, Wilson CJ, Young SJ, Rebec GV (1975) Self-inhibition by dopaminergic neurons. Science 190:522-528.

Gu X, Blatz AL, German DC (1992) Subtypes of substantia nigra dopaminergic neurons revealed by apamin: autoradiographic and electrophysiological studies. Brain Res Bull 28:435-440.

Guzman JN, Hernandez A, Galarraga E, Tapia D, Laville A, Vergara R, Aceves J, Bargas J (2003) Dopaminergic modulation of axon collaterals interconnecting spiny neurons of the rat striatum. J Neurosci 23:8931-8940.

Hajos M, Greenfield SA (1993) Topographic heterogeneity of substantia nigra neurons: diversity in intrinsic membrane properties and synaptic inputs. Neuroscience 55:919-934.

Harris AL (2001) Emerging issues of connexin channels: biophysics fills the gap. Q Rev Biophys 34:325-472.

Kita T, Kita H, Kitai ST (1986) Electrical membrane properties of rat substantia nigra compacta neurons in an in vitro slice preparation. Brain Res 372:21-30.

Komendantov AO, Canavier CC (2002) Electrical coupling between model midbrain dopamine neurons: effects on firing pattern and synchrony. J Neurophysiol 87:1526-1541.

Landisman CE, Long MA, Beierlein M, Deans MR, Paul DL, Connors BW (2002) Electrical synapses in the thalamic reticular nucleus. J Neurosci 22:1002-1009.

LeBeau FE, Traub RD, Monyer H, Whittington MA, Buhl EH (2003) The role of electrical signaling via gap junctions in the generation of fast network oscillations. Brain Res Bull 62:3-13. 
Leung DS, Unsicker K, Reuss B (2002) Expression and regulation of gap junction connexins cx26, cx32, cx43 and cx45 in the rat midbrain floor. Int J Dev Neurosci 20:63-75.

Lin JH, Weigel H, Cotrina ML, Liu S, Bueno E, Hansen AJ, Hansen TW, Goldman S, Nedergaard M (1998) Gap-junction-mediated propagation and amplification of cell injury. Nat Neurosci 1:494-500.

Lin JY, van Wyk M, Bowala TK, Teo MY, Lipski J (2003) Dendritic projections and dye-coupling in dopaminergic neurons of the substantia nigra examined in horizontal brain slices from young rats. J Neurophysiol 90:2531-2535.

Ljungberg T, Apicella P, Schultz W (1992) Responses of monkey dopamine neurons during learning of behavioral reactions. J Neurophysiol 67:145-163.

Marti MJ, James CJ, Oo TF, Kelly WJ, Burke RE (1997) Early developmental destruction of terminals in the striatal target induces apoptosis in dopamine neurons of the substantia nigra. J Neurosci 17:2030-2039.

Mereu G, Lilliu V, Casula A, Vargiu PF, Diana M, Musa A, Gessa GL (1997) Spontaneous bursting activity of dopaminergic neurons in midbrain slices from immature rats: role of $N$-methyl-D-aspartate receptors. Neuroscience 77:1029-1036.

Meyer AH, Katona I, Blatow M, Rozov A, Monyer H (2002) In vivo labeling of parvalbumin-positive interneurons and analysis of electrical coupling in identified neurons. J Neurosci 22:7055-7064.

Morris G, Arkadir D, Nevet A, Vaadia E, Bergman H (2004) Coincident but distinct messages of midbrain dopamine and striatal tonically active neurons. Neuron 43:133-143.

Neuhoff H, Neu A, Liss B, Roeper J (2002) $I_{\mathrm{h}}$ channels contribute to the different functional properties of identified dopaminergic subpopulations in the midbrain. J Neurosci 22:1290-1302.

Obeso JA, Rodriguez-Oroz MC, Rodriguez M, Lanciego JL, Artieda J, Gonzalo N, Olanow CW (2000) Pathophysiology of the basal ganglia in Parkinson's disease. Trends Neurosci 23:S8-S19.

Pucak ML, Grace AA (1994) Evidence that systemically administered dopamine antagonists activate dopamine neuron firing primarily by blockade of somatodendritic autoreceptors. J Pharmacol Exp Ther 271:1181-1192.

Reynolds JN, Wickens JR (2002) Dopamine-dependent plasticity of corticostriatal synapses. Neural Netw 15:507-521.

Romo R, Schultz W (1990) Dopamine neurons of the monkey midbrain: contingencies of responses to active touch during self-initiated arm movements. J Neurophysiol 63:592-606.

Rouach N, Segal M, Koulakoff A, Giaume C, Avignone E (2003) Carbenoxolone blockade of neuronal network activity in culture is not mediated by an action on gap junctions. J Physiol (Lond) 553:729-745.
Rozental R, Srinivas M, Spray DC (2001) How to close a gap junction channel. Efficacies and potencies of uncoupling agents. Methods Mol Biol 154:447-476.

Saez JC, Berthoud VM, Branes MC, Martinez AD, Beyer EC (2003) Plasma membrane channels formed by connexins: their regulation and functions. Physiol Rev 83:1359-1400.

Sanghera MK, Trulson ME, German DC (1984) Electrophysiological properties of mouse dopamine neurons: in vivo and in vitro studies. Neuroscience 12:793-801.

Schmitz D, Schuchmann S, Fisahn A, Draguhn A, Buhl EH, Petrasch-Parwez E, Dermietzel R, Heinemann U, Traub RD (2001) Axo-axonal coupling. A novel mechanism for ultrafast neuronal communication. Neuron 31:831-840.

Schultz W, Dayan P, Montague PR (1997) A neural substrate of prediction and reward. Science 275:1593-1599.

Seroogy K, Tsuruo Y, Hokfelt T, Walsh J, Fahrenkrug J, Emson PC, Goldstein M (1988) Further analysis of presence of peptides in dopamine neurons. Cholecystokinin, peptide histidine-isoleucine/vasoactive intestinal polypeptide and substance $\mathrm{P}$ in rat supramammillary region and mesencephalon. Exp Brain Res 72:523-534.

Shannon CE (1948) A mathematical theory of communication. Bell System Tech J 27:379-423, 623-656.

Skirboll LR, Grace AA, Bunney BS (1979) Dopamine auto- and postsynaptic receptors: electrophysiological evidence for differential sensitivity to dopamine agonists. Science 206:80-82.

Venance L, Premont J, Glowinski J, Giaume C (1998) Gap junctional communication and pharmacological heterogeneity in astrocytes cultured from the rat striatum. J Physiol (Lond) 510:429-440.

Venance L, Rozov A, Blatow M, Burnashev N, Feldmeyer D, Monyer H (2000) Connexin expression in electrically coupled postnatal rat brain neurons. Proc Natl Acad Sci USA 97:10260-10265.

Venance L, Glowinski J, Giaume C (2004) Electrical and chemical transmission between striatal GABAergic output neurones in rat brain slices. J Physiol (Lond) 559:215-230.

Veruki ML, Hartveit E (2002) AII (Rod) amacrine cells form a network of electrically coupled interneurons in the mammalian retina. Neuron 33:935-946.

Wilson CJ (1995) The contribution of cortical neurons to the firing pattern of striatal spiny neurons. In: Model of information processing in basal ganglia (Houk JC, David JL, Beiser DG, eds), pp 29-50. Cambridge, MA: MIT. 